\title{
Effect of cacao liquor extract on tumor marker enzymes during chemical hepatocarcinogenesis in rats.
}

\begin{abstract}
This study investigated the effect of cacao liquor extract (CLE) on tumor marker enzymesalkaline phosphatase (ALP), $\gamma$-glutamyl transpeptidase (GGT), glutathione-S-transferase (GST), and glutathione reductase (GR) activities-in plasma and/or liver of hepatocarcinogenic rats, which were induced with diethylnitrosamine and 2acetylaminofluorene. Twenty-nine male Sprague-Dawley rats (weighing 150-330 g) were divided into four groups $(\mathrm{n}=6-8)$ : normal control group $(\mathrm{N})$, normal group + CLE (NE), cancer group (C), and cancer group + CLE (CE). Analysis of variance showed significant differences $(\mathrm{P}<.05)$ in the specific activities of ALP, GGT, and GST between the C and $\mathrm{N}$ groups. However, GR activity for the $\mathrm{C}$ group was not significantly different compared with the $\mathrm{N}$ group. In the CE group, the specific activities of ALP, GGT, GST, and GR were significantly lower $(\mathrm{P}<.05)$ compared with the $\mathrm{C}$ group. The findings showed that CLE could lower the activity of tumor marker enzymes of rats during hepatocarcinogenesis. Based on the results obtained, polyphenol compounds present in the cacao liquor, extracted by using ethanol, have the potential in decreasing the severity of hepatocarcinogenesis.
\end{abstract}

Keyword: Cacao liquor; Hepatocarcinogenesis; Tumor marker enzymes. 